\title{
Utilização do recurso celular em sala de aula: realidades, aspectos e possibilidades
}

Lucas Vanini*, Andressa Gomes Paula**

\section{Resumo}

O presente artigo tem como principal finalidade investigar a utilização do recurso celular em sala de aula. Para tal, realizamos um questionário que foi distribuído aos professores da rede pública, no qual foram abordadas questões relacionadas à opinião desses sobre o uso de aplicativos de celulares em sala de aula. Entrevistamos quatorze professores da rede pública municipal de Passo Fundo. Dessa forma, com a análise dos questionários, articulamos os dados coletados nesse instrumento de pesquisa. Nesse viés, de acordo com os dados da pesquisa, visualizamos que parte dos docentes tem boa aceitação no uso de recursos digitais em suas aulas. No entanto, a pesquisa apontou um problema com a estrutura física oferecida nas escolas para essa prática. Também, parte dos sujeitos da pesquisa demonstrou resistência em desenvolver diferentes metodologias, atentando grande preocupação em vencer conteúdos propostos pelo currículo escolar. Nesse interim, entendemos que a pesquisa desencadeou a necessidade de continuar buscan- do respostas às questões sobre a utilização na sala de aula de tecnologias digitais como recurso no ensino e aprendizagem.

Palavras-chave: Ensino e Aprendizagem. Formação de professores. Tecnologias digitais.

\section{Introdução}

A estrutura de parte das escolas públicas não condiz com laboratório de ciências (COSTA et al., 2012), o que dificulta muito a prática de algumas experiências em sala de aula. Com essa realidade, durante todos esses anos, e com a ampliação do uso das TD em sala de aula, podemos ter no uso dos smartphones por nossos alunos, um recurso para auxiliar as explicações em diversas áreas, porém aqui focamos especificamente a área de

\footnotetext{
* Doutor em Ensino de Ciências e Matemática - Ulbra/Canoas, Professor do Instituto Federal Sul-rio-grandense - IFSul, Campus Passo Fundo. E-mail: lucas.vanini@passofundo.ifsul.edu.br

** Professora da rede Municipal de Ensino de Passo Fundo. E-mail: andressagpaula@hotmail.com
} 
ciências. Assim, justificamos o uso de alguns aplicativos para desenvolvimento de experiências científicas. Em diversas áreas, de forma interativa para o aluno do Século XXI.

Assim, a realidade da escola pública no país, faz com que tenhamos uma reflexão sobre como se pode desenvolver aulas com o uso de Tecnologias Digitais (TD), como recurso nos processos de ensino e de aprendizagem. Ao visualizarmos os recursos da escola pública atual, deparamo-nos com uma grande dificuldade em trabalhar aulas práticas de ciências, e trazendo ainda os problemas sociais dos alunos, em que muitas vezes a escola se torna um local de refúgio de suas vidas particulares.

Objetivamos trazer aulas práticas de forma digital para a sala de aula, e para isso, investigamos a aceitação dos professores na utilização de celulares como recurso na aprendizagem. Além disso, temos como objetivo nesse estudo também, investigar causas do uso ou do não uso de TD na sala de aula, além de aspectos na formação dos professores, ligados às TD e ainda como esses docentes visualizam o uso de celular em suas aulas. Nesse contexto, tendo como meta alcançarmos os objetivos propostos, buscamos nessa pesquisa respostas para a seguinte questão diretriz: como os docentes que trabalham no ensino fundamental de uma escola pública avaliam o uso do celular nas suas salas de aulas?
Nesse viés, organizamos o presente artigo com uma seção introdutória, seguido de um referencial teórico, continuando com a metodologia da pesquisa, na sequência, apresentamos a análise de dados, logo após, as considerações finais e referências.

\section{Referencial teórico}

Com o passar das gerações, as crianças estão mais críticas, com pensamentos formados, seguindo o que Darwin expôs na teoria da evolução das espécies, era disso que ele falava, não só da evolução biológica, mas, também, psicológica das espécies. E a raça humana está passando por essa evolução. Assim, a cada geração que nasce na humanidade a criticidade vai surgindo cada vez mais forte. Sentimos isso nas escolas, todos os dias.

A escola de hoje não é mais aquela em que o estudante somente recebia informações, mas, sim, algo muito mais complexo. Formamos cidadãos, com o objetivo de melhorar a sociedade atual. $\mathrm{E}$ isso nunca foi tão complicado como agora, já que nossas crianças chegam com pré-conceitos bem definidos.

Pesquisadores pensam, atualmente, a escola do jeito que ela se apresenta, após a Revolução Industrial - final do século XIX (RIBEIRO, 1993). Antes dessa data, a escola estava vinculada à Igreja e seus seguidores. Apenas esses tinham o privilégio do ensino. Mas isso mudou 
e mudou bastante, depois dessa Revolução, foram inseridos cada vez mais, diversos grupos de pessoas no ambiente escolar, até se chegar aos dias atuais, quando se tem um índice bem baixo de crianças que não frequentam a escola $\mathrm{e}$ um nível baixíssimo de analfabetismo.

A escola atual não é mais uma simples "transmissora" de conteúdos, que trata o aluno de forma isolada, e sim, num contexto de convivência. Não pensamos a escola como um professor isolado, mas, sim, num ambiente com outras pessoas que fazem parte de seu cotidiano. $\mathrm{O}$ que engloba os processos de ensino e de aprendizagem é muito mais que isso. Entendemos que ocorre nas escolas uma troca de conhecimentos entre alunos e professores e vice-versa, em momentos de debates de ideias, não necessariamente erradas, e sim diferentes. As ideias e conhecimentos não têm limites físicos, diferente daquela ideia inicial de classes, cadeiras, quadro e giz. Mesmo porque, nem precisamos de uma sala de aula para construir o conhecimento, a tecnologia aparece, quebrando todos esses parâmetros. Nossos alunos permanecem quase as 24 horas do dia on-line em seus smartphones, e cremos que precisamos usar isso a favor da educação, da construção do conhecimento, pois se os estudantes,
[...] veem e ouvem o desprezo, o tédio, a impaciência do professor, aprendem, uma vez mais, que são pessoas que inspiram desgosto e enfado. Se percebem o entusiasmo do professor quando este lida com seus próprios momentos de vida, podem descobrir um interesse subjetivo na aprendizagem crítica (ORTH; BAGGIO, 2001. p. 119).

Nesse viés, entendemos que o processo pedagógico pode iniciar a partir do conhecimento prévio de realidade do aluno (ALVES; GARCIA, 1986). Assim, aluno e professor juntos, poderão construir o conhecimento, esse saber que o aluno traz consigo, nunca deve ser desperdiçado pelo professor, que também é um construtor do seu conhecimento, e esta construção nunca se conclui, sempre deve-se buscar algo para complementar. Independente de aluno ou o professor, o conhecimento é algo que sempre se está em busca. Cabe ao professor saber direcionar esta busca ao conhecimento para algo bom. Nesse sentido, o uso de celulares na sala de aula, pode ser um aliado, quando bem direcionado.

O conhecimento é amplo, e sem barreiras. Mas para que aconteça uma sequência evolutiva deste, precisa-se de organização de profissionais que trabalham esse conhecimento e de papéis que irão focar as necessidades da comunidade escolar (MANZANO, 2007). Sem esses e outros fatores importantes, não se consegue uma transformação progressiva no 
ambiente escolar. Somente dessa forma conjunta, a escola continuará avançando.

Assim, concordamos com Grinspun (2002) ao defender o conhecimento como sistemático e universal, e a educação tendo uma função social e política na formação da cidadania. Mesmo porque objetivamos formar seres críticos de mundo. Cremos que a sociedade precisa de "pensadores", mas não aqueles que se dedicam a formular teorias sobre os mais diversos assuntos, esses são importantes, mas também a necessidade de cidadãos conscientes de suas atitudes e opiniões, capazes de interagir de maneira ativa com as questões sociais da atualidade.

Aprender é um direito de todo o cidadão (BRASIL, 1988), e está garantido nas leis que regem este país. Desde o nascimento até a morte, o ser humano é um ser que aprende. Tudo que ocorre desde os primeiros contatos do recém-nascido são momentos de apreensão de ensinamentos, mesmo os instintivos, são aprendidos. E na vida adulta o ser humano continua a aprender uma coisa ou outra. Mas quando se fala em aprender, cultura e outros termos, se faz a relação direta com a escola, que não é uma relação equivocada, já que se sabe que a escola é o lugar onde a função é esta, e o cotidiano é aprender.

Essa "disputa" entre teoria e prática também ocorre na educação, já que o educador, para se formar como tal, tem a teoria e na hora que entra na sala de aula começa a fazer sua prática. Com o passar dos anos e com as experiências construídas, alguns educadores podem diminuir a distância entre as duas. Outros, no entanto, permanecem com as mesmas concepções.

Em questões de prática hoje a educação sofre com a divisão de profissionais, existem aqueles que permanecem no âmbito tradicional e por determinadas razões defendem essa postura (MANZANO, 2007). E em outro extremo, aparece aquele educador inovador, se baseando em teorias atuais, onde constrói sua prática mais flexível aos problemas da realidade e da comunidade escolar em si. Não queremos defender ou criticar que o educador tradicional é um alienado e não se preocupa com sua escola. Apenas esclarecemos que são preocupações diferentes, pois cada educador tem suas particularidades, e como se sabe não existe receita do certo ou errado a nível escolar. Sendo assim, concordamos com Alves e Garcia, quando defendem a função social da escola, ou seja,

[...] em todos os tempos, em todas as sociedades, seja qual for o sistema político, sempre teve uma função muito clara - a de transmitir para as novas gerações o conhecimento acumulado pelas gerações que as antecederam. À questão central da escola é a socialização do conhecimento (1986. p. 13).

Dessa forma, a partir desses pontos de vista, esta não pode, portanto, as- 
sumir um papel apenas de repasse de conteúdos, mas estimular o desenvolvimento de um pensar ágil, reflexivo e criativo, elementos essenciais no cotidiano de um cidadão crítico e participativo atualmente. Nesse contexto,

[...] o papel da escola é promover o desenvolvimento do indivíduo, tornando-o capaz de enfrentar múltiplas situações porque conta com uma bagagem valiosa de experiências e apresenta um raciocínio sempre aberto ao estabelecimento de novas relações com o mundo que o cerca (GRINSPUN, 1996, p. 130).

Nesse ínterim, de acordo com Paulo Freire (1986), a educação possui um caráter extremamente transformador, cabendo ao educador, um ser político, direcionar de maneira eficiente, através de sua práxis, o processo de construção e desenvolvimento das aprendizagens.

O processo de aprendizagem ocorre individualmente, e cabe ao docente perceber o tempo de cada aluno, pois estamos vivenciando uma desvalorização da escola atual. Nesse sentido, concordamos com Cortella ao defender que, alguns

[...] desistem de tentar aprender. Isso era incomum. Hoje nós temos isso numa outra esfera, que a escola é desinteressante e se entende que é o aluno que não se interessa. Se ele não se interessa, tem transtorno de déficit de atenção e hiperatividade (TDAH). Como não existe medicamento para a escola tomar, dado a abstração, é mais prático dar algum remédio para 0 menino (2015, p. 108).
Nesse contexto, acreditamos que é necessário que o professor

[...]saiba refletir/discutir sobre os temas pedagógicos, sobre os conteúdos específicos da sua área de atuação, bem como sobre os recursos tecnológicos que podem ser utilizados no ambiente educativo, constituindo outras possibilidades no contexto de sua prática (VANINI, 2011, p. 53)

Diante do exposto, entendemos que, o uso das tecnologias como recurso, pode trazer de volta a emoção de aprender, e principalmente o popular smartphone, poderá se tornar um recurso aliado nessa busca incessante do professor trazer esse aluno, não só de corpo, mas de mente e coração para o ambiente escolar.

A partir das informações alcançadas neste referencial teórico, seguimos para a pesquisa de campo nas escolas selecionadas.

\section{Metodologia}

A presente pesquisa trata-se de uma abordagem qualitativa, pois conforme Gerhardt, a pesquisa qualitativa,

[...] não se preocupa com representatividade numérica, mas, sim, com o aprofundamento da compreensão de um grupo social, de uma organização, etc. Os pesquisadores que adotam a abordagem qualitativa opõem-se ao pressuposto que defende um modelo único de pesquisa para todas as ciências, já que as ciências sociais têm sua especificidade, o que pressupõe uma metodologia própria (2009, p. 31). 
Inicialmente, foram escolhidas as escolas, o critério utilizado para escolha foi escola em que trabalho atualmente, selecionando os professores de ensino fundamental I e II, juntamente com a equipe diretiva de duas escolas selecionadas.

A primeira escola selecionada foi a Escola Municipal de Ensino Fundamental Santo Agostinho, situada na Avenida Alceus Laus número 789, no bairro Nenê Graeff, na cidade de Passo Fundo. Essa escola é composta de 224 alunos, 17 professores, 5 funcionárias e 1 diretora.

Nessa escola, os questionários foram entregues para 7 professores, do ensino fundamental I e II, ainda para a diretora e para as duas coordenadoras, da manhã e da tarde. No entanto, foram devolvidos apenas os questionários de 4 professores, da diretora e das duas coordenadoras.

A segunda escola selecionada foi a Escola Municipal de Ensino Fundamental Benoni Rosado, situada na Rua Dep. Fernando Ferrari número 189, no bairro São José, na cidade de Passo Fundo. Essa escola é composta por 215 alunos, 19 professores, 6 funcionários e 1 diretora.

Nessa escola, os questionários foram entregues para 8 professores, do ensino fundamental I e II, ainda para a diretora e para a coordenadora dos anos iniciais. No entanto, foram devolvidos apenas os questionários de 5 professores, da diretora e da coordenadora.
O questionário foi aplicado no período de 03/10/2017 a 07/11/2017 e contou com as seguintes perguntas dissertativas (Quadro 1):

Quadro 1 - Perguntas dissertativas

Na sua opinião, a educação no ensino fundamental necessita de "novos" recursos? Por quê? Quais?

Como você visualiza o uso de tecnologias digitais em sala de aula?

Os educadores do século XXI estão preparados para essa evolução atual? Justifique.

As formações de professores estão de acordo com a preparação no uso de tecnologias digitais disponíveis na escola? De que forma?

Você se imagina utilizando celulares como recurso em suas aulas? Por quê?

$\mathrm{Na}$ sua opinião, o uso de tecnologias digitais pode beneficiar a aprendizagem da educação inclusiva? Por quê? De que forma?

Alguns ambientes educacionais não disponíveis na escola (laboratórios, museus, monumentos), podem ser reproduzidos de forma virtual. Você acredita que esse recurso pode ser um aliado do professor no processo de ensino e de aprendizagem? Justifique.

A equipe diretiva de sua escola apoia e/ou incentiva o uso de tecnologias digitais em sala de aula? De que forma?

Fonte: autores (2018).

Com os questionários respondidos, fizemos a análise das respostas de ambas as escolas. Apresentamos os resultados sob a forma comparativa de cada questão. 


\section{Dados e análise}

Apresentamos os dados, e por organização, chamamos a Escola Municipal de Ensino Fundamental Santo Agostinho de E. 1, e a Escola Municipal de Ensino Fundamental Benoni Rosado de
E. 2, assim como os professores de prof. A, prof. B, e assim por diante, de acordo com a numeração dada nos questionários. Para nossa análise, foram selecionadas duas respostas de cada pergunta por escola, conforme pode ser conferido no Quadro 2.

Quadro 2 - Respostas da questão 1

$\mathrm{Na}$ sua opinião, a educação do ensino fundamental necessita de "novos" recursos? Por quê? Quais?
(E. 1; Prof. A) Penso que a primeira reação dos professores diante dos avanços tecnológicos é a rejeição, pelo fato de não estarem familiarizados com os recursos. Quando este primeiro "choque" passar, acredito que a introdução de novos recursos na educação será automática, pois são absolutamente necessários.

(E. 1; Prof. B) Sempre precisamos de novos recursos e metodologias. Vivenciando um período em que as informações e novos conceitos surgem com grande velocidade e a escola precisa acompanhar tudo isso. Creio ser necessários tablet's para todos os alunos, internet que comporte a demanda.

(E. 2; Prof. C) Faz-se necessário o incremento de mais e novos que auxiliem na aprendizagem, como é sabido quanto mais vivência e experiência, o usufruir maior será a facilidade de aprender, portanto quanto mais recursos houver melhor será a evolução intelectual do aluno. Os recursos deveriam estar melhor dispostos e acessíveis como laboratórios, testes e novidades.

(E. 2; Prof. D) Sim, para uma maior e melhor abordagem do conteúdo para o aluno. Retroprojetor nas salas, ábacos, e toda a espécie de material concreto e visual para que a turma possa acessar e manusear, fazendo assim com que o aluno participe, se envolva e interaja.

Fonte: autores (2018).

Sendo assim, entendemos que os professores admitem que a educação precisa de novos recursos pois há uma grande evolução nesse sentido por parte dos alunos e a escola precisa acompanhar essa demanda.

De acordo com o relato do Prof. A (E.1), “[...]a primeira reação dos professores diante dos avanços tecnológicos é a rejeição, pelo fato de não estarem familiarizados com os recursos [...]" entendemos que a maioria dos professores não teve na sua formação, o uso das tecnologias, e por isso se sentem alienados em relação à isso, causando essa rejeição. Já o Prof. B (E.1), relata o grande problema da internet nas escolas públicas, cremos que, possivelmente, a 
falta dessas condições adequadas acaba somando para uma rejeição.

Na fala do Prof. C (E.2) "[...]quanto mais recursos houver melhor será a evolução intelectual do aluno [...]", re- conhecemos a necessidade que se tem nas escolas dessa evolução, trazendo a aprendizagem como algo incessante para todos, o que é confirmado com o relato do Prof. D (E.2).

Quadro 3 - Respostas da questão 2

Como você visualiza o uso de tecnologias digitais em sala de aula?
(E. 1; Prof. B) O uso é bastante limitado. Em geral, são trabalhados conteúdos através do data-show, repassando os assuntos por meio de vídeos e filmes. As pesquisas na internet são limitadas devido a qualidade do serviço ofertado pela rede para a escola.

(E. 1; Prof. C) Uma dádiva e um perigo. Uma dádiva, pela questão que os alunos e o professor podem transformar e ampliar os horizontes do ensino e alcançar lugares pouco explorados e cheios de recursos áudio visuais, e um perigo, pois as tecnologias que normalmente gostamos, nos ensinam a ter menos paciência, tendo como consequência menos tempo de concentração.

(E. 2; Prof. A) Os alunos de hoje são muito visuais e aprendem com facilidade quando o assunto é tecnologia. Eles se cansam facilmente das práticas repetitivas do ensino tradicional. Nesse sentido a tecnologia bem aplicada passa ser um facilitador no acesso a informação e a aprendizagem.

(E. 2; Prof. C) De boa maneira, visto que é parte constante de nossas vidas e sempre e mais surgirão coisas novas e fundamentais à nossa vida. A cada ano surgem novas tecnologias que são utilizadas pois que facilitam o estudo e sua aplicação nos empregos futuros de nossos alunos.

Fonte: autores (2018).

Nesse caso, podemos salientar que os professores acreditam ser positivo o uso de TD em sala de aula, no entanto alguns tem receio que essa aceleração do mundo virtual possa acarretar a falta de concentração dos alunos.

Conforme Prof. B (E.1),

[...] Em geral, são trabalhados conteúdos através do data-show, repassando os assuntos por meio de vídeos e filmes. As pesquisas na internet são limitadas devido a qualidade do serviço ofertado pela rede para a escola.
Cremos que o uso dessa tecnologia se torna limitado e novamente é citado o problema da internet nas escolas. Já para o Prof. C (E.1),

[...] Uma dádiva, pela questão que os alunos e o professor podem transformar e ampliar os horizontes do ensino e alcançar lugares pouco explorados e cheios de recursos áudio visuais, e um perigo, pois as tecnologias que normalmente gostamos, nos ensinam a ter menos paciência [...].

Percebemos a insegurança dos professores em relação ao mundo acelerado 
da tecnologia em relação a impaciência natural dos nossos jovens.

Com relação ao relato do Prof. A (E.2), “[...] a tecnologia bem aplicada passa ser um facilitador no acesso à informação e a aprendizagem”. Percebemos que há uma tendência dessa aceitação pelo novo e o Prof. C (E.2) apenas confirma o relato anterior "[...] A cada ano surgem novas tecnologias que são utilizadas pois que facilitam o estudo e sua aplicação nos empregos futuros de nossos alunos".

Quadro 4 - Respostas da questão 3

Os educadores do século XXI estão preparados para essa evolução atual? Justifique.
(E. 1; Prof. A) A maioria não está preparada, mas acredito que grande parte já está se "abrindo" para essa evolução. Na verdade, esse é um caminho sem volta, pois a tecnologia disponível hoje ainda vai evoluir muito e não haverá possibilidade de ninguém ficar de fora dessa evolução.

(E. 1; Prof. D) Nem sempre. Existem educadores que pararam no tempo e não aceitam as novas mudanças e isso, muitas vezes, gera conflitos em sala de aula.

(E. 2; Prof. A) O professor como principal fonte do ensino deve criar condições e viabilizar novas formas de ação para que ocorra a aprendizagem mas ainda tem muitas limitações no que se refere a tecnologia. O professor ainda não possui habilidades e interesse em informatizar o conhecimento.

(E. 2; Prof. B) Os educadores do século XXI tem muito a contribuir no campo da ética, contudo uma grande parcela dos que ainda estão à frente da educação receberam sua formação sem a utilização de tecnologias digitais, o que os deixa em desvantagem, mesmo buscando se inteirar das mudanças. Importa a troca de experiências entre as gerações.

Fonte: autores (2018).

De acordo com as respostas apresentadas podemos dizer que a maioria dos educadores não se sente preparada para essa evolução tecnológica. Admitem ser necessária, mas se consideram despreparados.

Concordamos com o Prof. A (E.1), quando diz que

[...] esse é um caminho sem volta, pois a tecnologia disponível hoje ainda vai evoluir muito e não haverá possibilidade de ninguém ficar de fora dessa evolução.
Pois com todos os outros aspectos evolutivos da atualidade foi assim, primeiro houve a rejeição e por fỉm a aceitação. Essa rejeição inicial é relatada pelo Prof. D (E.1)

[...] Existem educadores que pararam no tempo e não aceitam as novas mudanças e isso, muitas vezes, gera conflitos em sala de aula.

Aqui, observamos que os alunos estão totalmente abertos ao novo, mas al- 
guns professores podem não aceitar essa modalidade, gerando grandes conflitos.

O relato do Prof. A (E.2), nos traz para a triste realidade e desmotivação dos nossos educadores, “[...] O professor ainda não possui habilidades e interesse em informatizar o conhecimento". Já o Prof. B (E.2), justifica essa questão colocada pelo Prof. A (E.2),
[...] uma grande parcela dos que ainda estão à frente da educação receberam sua formação sem a utilização de tecnologias digitais, o que os deixa em desvantagem, mesmo buscando se inteirar das mudanças. Importa a troca de experiências entre as gerações.

Dessa forma, entendemos que mesmo com essa dificuldade, uma grande parcela de docentes ainda busca atualização.

\section{Quadro 5 - Respostas da questão 4}

As formações de professores estão de acordo com a preparação no uso de tecnologias digitais disponíveis na escola? De que forma?
(E. 1; Prof. A) As formações de professores estão muito aquém da real necessidade de atualização dos professores, principalmente no que diz respeito à preparação para o uso de tecnologias digitais. Desde locais inadequados para os encontros de formação até temas não relevantes e, passando também pela falta de motivação dos professores. A estrutura das escolas também não é uniforme, pois algumas dispõem de recursos que não estão disponíveis em outras, ou que funcionam com precariedade.

(E. 1; Prof. B) Poucos são os profissionais capacitados que se disponibilizam a fazer esse trabalho nas escolas. Em geral, fazemos estudos teóricos sobre o tema e através da prática diária vamos aprendendo uns com os outros.

(E. 2; Prof. A) Sabemos que os recursos digitais disponíveis nas escolas públicas são limitados, devido à isso o interesse em formar profissionais com conhecimento na área de tecnologia não existe. Cabe ao professor ir em busca dessa formação.

(E. 2; Prof. B) Nas escolas onde trabalho, os laboratórios de informática estão sucateados, antigos, impróprios para produtividade e qualidade. A formação dos professores acompanha essa deficiência: em parte porque boa parcela dos mesmos estão no aguardo da aposentadoria e já não querem mais investir em sua formação e em parte pelas dificuldades que os professores estão passando pelo não investimento em educação por parte do Estado.

Fonte: autores (2018).

Nesse caso, a resposta dos professores foi quase unânime. Admitem que falta formação continuada de professores na área e, junto a isso, existe o sucateamento dos recursos digitais nas escolas. Com isso, percebemos uma desmotivação de vários. Observe-se a resposta do Prof. A (E.1): 
As formações de professores estão muito aquém da real necessidade de atualização dos professores, principalmente no que diz respeito à preparação para o uso de tecnologias digitais. Desde locais inadequados para os encontros de formação até temas não relevantes e, passando também pela falta de motivação dos professores. A estrutura das escolas também não é uniforme, pois algumas dispõem de recursos que não estão disponíveis em outras, ou que funcionam com precariedade.

Considerando isso, podemos perceber que é uma fala da maioria, em que reconhecem a necessidade de formação continuada que aborde aspectos de TD no ensino e aprendizagem.

Já o Prof. B (E.2) destaca outra questão importante

[...] no aguardo da aposentadoria e já não querem mais investir em sua formação e em parte pelas dificuldades que os professores estão passando pelo não investimento em educação por parte do Estado.

Com isso, entendemos que questões políticas e sociais também colaboram para a falta de motivação desses professores.

Quadro 6 - Respostas da questão 5

\begin{tabular}{|c|c|}
\hline $\begin{array}{l}\text { Você se imagina utilizando } \\
\text { celulares como recurso em } \\
\text { suas aulas? Por quê? }\end{array}$ & $\begin{array}{l}\text { (E. 1; Prof. A) Sim, o celular está presente em todos os momentos da } \\
\text { vida de qualquer pessoa. Trazê-lo para dentro da sala de aula me pa- } \\
\text { rece algo natural. Existem recursos, muitos aplicativos que facilitam } \\
\text { a aprendizagem e dão um caráter mais dinâmico às aulas, tornando- } \\
\text {-as, assim, mais atrativas. } \\
\text { (E. 1; Prof. C) Não, falta paciência para os alunos e muitas são as } \\
\text { tecnologias diferentes. } \\
\text { (E. 2; Prof. C) Não me imagino porque não estou preparado, mas } \\
\text { acho que é fundamental, visto que oferece muitos recursos. } \\
\text { (E. 2; Prof. E) Não, porque os alunos hoje em dia são muito rápidos } \\
\text { e acessam outros sites desnecessários ao trabalho em sala de aula. }\end{array}$ \\
\hline
\end{tabular}

Fonte: autores (2018).

Analisando essas respostas, percebemos que a maioria dos professores não se imagina utilizando essa tecnologia, principalmente por não se sentirem preparados para esse uso.

O Prof. A (E.1) assevera “[...] o celular está presente em todos os momentos da vida de qualquer pessoa [...]", percebemos que alguns professores já trazem isso para sua realidade em sala de aula.
No entanto, o Prof. C (E.1) destaca que "[...] falta paciência para os alunos [...]", percebemos aqui uma falta de motivação para a atualização.

Nesse contexto, o Prof. C (E.2) relata “[...] Não me imagino porque não estou preparado, mas acho que é fundamental, visto que oferece muitos recursos". Entendemos que esse professor assume a dificuldade, mas admite a necessidade. 
Já o Prof. E (E.2) reproduz uma preocupação quando diz "[...]os alunos hoje em dia são muito rápidos e acessam outros sites desnecessários [...]" entendemos aqui que existem aspectos desfavoráveis ao uso das TD em sala de aula.

\section{Quadro 7 - Respostas da questão 6}

\begin{tabular}{|l|l|}
\hline & $\begin{array}{l}\text { (E. 1; Prof. A) Desde que todos tenham acesso a essas tecnologias } \\
\text { e não esbarrem na precariedade de estruturas, computadores, inter- } \\
\text { net e, tenham profissionais preparados para auxiliá-los durante o uso } \\
\text { de equipamentos e demais atividades, o uso de tecnologias digitais } \\
\text { só traz benefícios, pois promove a inclusão ao universo tecnológico } \\
\text { que nos circunda nos mais variados contextos. } \\
\text { (E. 1; Prof. E) Sim, desde que tenha acompanhamento efetivo e não } \\
\begin{array}{l}\text { Na sua opinião, o uso de } \\
\text { tecnologias digitais pode } \\
\text { beneficiar a aprendizagem } \\
\text { quê? De que forma? }\end{array}\end{array}$ \\
$\begin{array}{l}\text { como mero passatempo. } \\
\text { (E. 2; Prof. A) A tecnologia também pode garantir a aprendizagem } \\
\text { dos alunos incluídos colaborando para que barreiras sejam supera- } \\
\text { das e a aprendizagem ocorra de forma mais satisfatória. Atividades } \\
\text { lúdicas e interativas, jogos e brincadeiras. } \\
\text { (E. 2; Prof. B) Penso que sim e muito. Além de ampliar muito as } \\
\text { possibilidades para quem se encontra em situação restrita, são fer- } \\
\text { ramentas de fácil manejo e permitem a comunicação com maior qua- } \\
\text { lidade, além de, em muitos casos, substituir membros lesados ou } \\
\text { inexistentes. }\end{array}$ \\
\hline
\end{tabular}

Fonte: autores (2018).

Um aspecto percebido ao analisarmos essas concepções, consiste em uma universalização de respostas, pois muitos afirmam que desde que haja planejamento e estrutura física, a educação inclusiva só tende a ganhar.

Nesse viés, o Prof. A(E.1) afirma que

Desde que todos tenham acesso a essas tecnologias e não esbarrem na precariedade de estruturas, computadores, internet e, tenham profissionais preparados para auxiliá-los durante o uso de equipamentos e demais atividades, o uso de tecnologias digitais só traz benefícios, pois promove a inclusão ao universo tecnológico que nos circunda nos mais variados contextos.
Percebemos nessa fala que ele concorda com vários benefícios das tecnologias na educação inclusiva, no entanto existe a preocupação com a estrutura física oferecida pela escola.

Inclusive, o Prof. A (E.2) nos deixa otimistas quando relata que "A tecnologia também pode garantir a aprendizagem dos alunos incluídos colaborando para que barreiras sejam superadas e a aprendizagem ocorra de forma mais satisfatória. Atividades lúdicas e interativas, jogos e brincadeiras", pois, enxergamos nesse relato a consciência de que o uso dos aplicativos de celulares pode ser um bom recurso. 
Quadro 8 - Respostas da questão 7

Alguns ambientes educacionais não disponíveis na escola (laboratórios, museus, monumentos), podem ser reproduzidos de forma virtual. Você acredita que esse recurso pode ser um aliado do professor no processo ensino e de aprendizagem? Justifique.
(E. 1; Prof. A) A experiência sensório-motora jamais será substituída pela experiência virtual, mas tendo em vista a situação precária das escolas quanto aos espaços destinados a laboratórios, bibliotecas e outros, às vezes a apresentação/reprodução desses espaços de forma virtual acaba sendo o único caminho para enriquecer as aulas e explorar novos.

(E. 1; Prof. B) Sim. Se o professor for conhecedor destes subsídios conseguirá tornar suas aulas mais significativas e interessantes.

(E. 2; Prof. A) O uso de tecnologia em sala de aula desperta o interesse dos alunos e estimulam a participação dos mesmos no processo da construção do conhecimento. Nesse sentido se o professor souber preparar suas aulas, fazer um bom planejamento e aplicar de forma correta e bem direcionada com certeza será um ótimo aliado.

(E. 2; Prof. B) Não só acredito como tenho convicção que sim. Fazer as crianças viajar pelo mundo virtual ao encontro do mundo real, certamente enriquecerá a memória e amplificará a curiosidade própria do ser humano. Há que se alertar para a malícia que também é humana.

Fonte: autores (2018).

Os professores acreditam que a reprodução do mundo real, não disponível para os alunos, de forma virtual pode contribuir com a aprendizagem. Acreditamos que essa é uma ideia com boa aceitação.

O Prof. A(E.1) aponta a comparação entre o real e o virtual quando coloca que

A experiência sensório-motora jamais será substituída pela experiência virtual, mas tendo em vista a situação precária das escolas quanto aos espaços destinados a laboratórios, bibliotecas e outros, às vezes a apresentação/reprodução desses espaços de forma virtual acaba sendo o único caminho para enriquecer as aulas e explorar novos.
O Prof. B (E.1) complementa dizendo

[...] Se o professor for conhecedor destes subsídios conseguirá tornar suas aulas mais significativas e interessantes.

Assim, finalizamos com o Prof. B (E.2) relatando

[...] Fazer as crianças viajar pelo mundo virtual ao encontro do mundo real, certamente enriquecerá a memória e amplificará a curiosidade própria do ser humano [...].

Nesse caso, percebemos que os professores têm uma ótima aceitação de quando o mundo real está inacessível, o mundo virtual poderá ser um grande aliado. 
Quadro 9 - Respostas da questão 8

A equipe diretiva de sua escola apoia e/ou incentiva o uso de tecnologias digitais em sala de aula? De que forma?
(E. 1; Prof. A) Num primeiro momento o uso de tecnologias digitais assuntou um pouco a direção (celulares), mas com o passar do tempo, essas situações foram superadas. Nossa escola não dispõe de muitos recursos e aqueles que estão disponíveis ficam guardados em armários chaveados e, cada vez que se usa, é preciso "montá-los" e "desmontá-los".

(E. 1; Prof. D) Muitas vezes quem não aceita as tecnologias são os próprios professores. A equipe gestora ao meu ver apoia, incentiva o uso. Sou totalmente a favor.

(E. 2; Prof. A) Sim, através do projeto de informática oferecido desde os anos iniciais (com aulas semanais) como também uma sala bem equipada com computadores individuais para os alunos. A equipe dos professores também tem acesso a equipamentos modernos como sons, televisores e computadores onde pode-se usar a internet.

(E. 2; Prof. B) A equipe diretiva considera a legislação vigente, incentiva o uso orientado com a presença do professor, desde que atenda a um objetivo pedagógico previamente estabelecido.

Fonte: autores (2018).

De acordo com as respostas dos professores, cremos que grande parte da equipe diretiva das escolas pesquisadas incentiva o uso das TD, o que muitas vezes acontece é a não aceitação por parte dos professores.

Conforme o relato do Prof. A (E.1), Num primeiro momento o uso de tecnologias digitais assuntou um pouco a direção (celulares), mas com o passar do tempo, essas situações foram superadas. Nossa escola não dispõe de muitos recursos e aqueles que estão disponíveis ficam guardados em armários chaveados e, cada vez que se usa, é preciso "montá-los" e "desmontá-los".

Percebemos que, num primeiro momento, foi polêmico esse recurso, mas também notamos que a questão da estrutura física das escolas aparece novamente como problema maior. No entanto, analisando o relato dos outros professores podemos perceber o incentivo da equipe diretiva, como afirma o Prof. B (E.2):

[...] A equipe diretiva considera a legislação vigente, incentiva o uso orientado com a presença do professor, desde que atenda a um objetivo pedagógico.

\section{Consideraçōes finais}

Esse trabalho teve como objetivo investigar a utilização do recurso celular em sala de aula por professores da rede pública municipal bem como a aceitação da equipe diretiva com relação a essa metodologia. Para isso, buscamos responder a seguinte pergunta: como os docentes que trabalham no ensino fundamental 
de uma escola pública avaliam o uso do celular nas suas salas de aulas?

De acordo com as repostas, podemos considerar que há uma divisão de opiniões, bem como algumas dificuldades de estrutura. Acreditamos que, devido aos dados apresentados, o objetivo geral foi alcançado, pois investigamos a aceitação dos professores na utilização de celular em sala de aula. Os demais objetivos também foram alcançados, pois buscamos as causas do uso/ou não de tecnologias digitais na sala de aula. Além disso, buscamos entender os aspectos na formação de professores ligados à tecnologia digital e as formas como os professores visualizam o uso de celular em sala de aula, e se os mesmos devem buscar mais conhecimentos e aprimoramento das práticas digitais.

Nesse ínterim, de acordo com a análise dos dados da pesquisa, entendemos que alguns professores manifestam uma aceitação ao uso de recursos digitais em suas aulas, mas tem um sério problema com a estrutura física oferecida nas escolas para essa prática, outros professores apresentam certa resistência em desenvolver atividades inovadoras, esses últimos, apresentam uma preocupação maior em vencer conteúdos e chegar na aposentadoria. Ainda salientamos a resistência de uma professora em responder o questionário.

Sendo assim, acreditamos que o atual estudo desencadeou a necessidade de continuarmos buscando respostas às nossas questões sobre a utilização de TD como recurso no ensino e na aprendizagem de ciências, visando à construção do conhecimento.

\section{Smartphone pedagogic usage: realities, aspects and possibilities}

\section{Abstract}

The main purpose of this article is to investigate the use of the cellular resource in the classroom. To do this, we carried out a questionnaire that was distributed to the public school teachers, in which questions related to their opinion about the use of mobile phone applications in the classroom were addressed. We interviewed fourteen teachers from the municipal public network of Passo Fundo. Thus, with the analysis of the questionnaires we articulate the data collected in this research instrument. In this bias, according to the research data, we visualize that some of the teachers have good acceptance in the use of digital resources in their classes. However, the research pointed out a problem with the physical structure offered in schools for this practice. Also, some of the subjects of the research demonstrated resistance in developing different methodologies, paying great attention to overcoming content proposed by the school curriculum. In the meantime, we understand that the research has triggered the need to continue seeking answers to the questions about the use of digital technologies as a resource in teaching and learning in the classroom.

Keywords: Teaching and learning. Teacher training. Digital technologies. 


\section{Referências}

ALVES, Nilda; GARCIA, Regina Leite. $O$ fazer e o pensar dos supervisores e orientadores educacionais. São Paulo: Edições Loyola, 1986.

BRASIL. Constituição da República Federativa do Brasil. Brasília, DF: Senado Federal: Centro Gráfico, 1988.

CORTELLA, Mario Sergio. Educação, convivência e ética: audácia e esperança. São Paulo: Cortez, 2015.

COSTA et al., Layla Fernada Souza. Principais dificuldades para o ensino de ciências na concepção de professores de escolas estaduais na cidade de Araguatins - TO. In: CONGRESSO NORTE NORDESTE DE PESQUISA E INOVAÇÃO, 7, 2012, Palmas, TO. Anais... Palmas, TO: Instituto Federal de Educação, Ciência e Tecnologia do Tocantíns - IFTO, 2012. Disponível em: <propi.ifto.edu.br/ocs/índex.php/ connepi/vii/paper/view/3155/237>. Acesso em: 10 nov. 2017.

FREIRE, Paulo. Pedagogia da autonomia: saberes necessários à prática educativa. 33. ed. São Paulo: Paz e Terra, 1996.

GERHARDT, Tatiana Engel; SILVEIRA, Denise Tolfo. Métodos de pesquisa. Porto Alegre: Editora da UFRGS, 2009.

GRINSPUN, Mirian Paura S. Zippin et al. A prática dos orientadores educacionais. 2. ed. São Paulo: Cortez, 1996. 158 p.

GRINSPUN, Mirian Paura S. Zippin. A orientação educacional: conflito de paradigmas e alternativas para a escola. 2. ed. São Paulo: Cortez, 2002.

MANZANO, Cinthia Soares. A formação de professores e a questão da diversidade na escola: análise de uma experiência de pesquisa-ação. In: Congresso Estadual Paulista sobre formação de educadores, 9, 2007, São Paulo. Anais... São Paulo: Unesp, 2007. Disponível em: <www.unesp.br/prograd/ixcepfe/Arquivos\%20 2007/1eixo.pdf>. Acesso em: 10 nov. 2017.
ORTH, Mara Rubia; BAGGIO, André. Crise paradigmática: complexidade na orientação educacional. Erechim: Edifapes, 2001.

RIBEIRO, Paulo Rennes Marçal. História da educação escolar no Brasil: notas para uma reflexão. Paidéia. Ribeirão Preto, n. 4, p. 15-30, fev./jul. 1993. Disponível em: <www. scielo.br/scielo.php?script=sci_arttext\&pid=S0103-863X1993000100003>. Acesso em: 10 nov. 2017.

VANINI, Lucas; ROSA, Maurício. Investigando a concepção de uso de tecnologias de informação e comunicação nas aulas de matemática no Instituto Federal de Educação, Ciência e Tecnologia Sul-Rio-Grandense, Campus Passo Fundo. Educação Matemática em Revista, Passo Fundo, v. 1, n. 12, p. 51-59, 2011. 